\section{Index of consciousness monitoring is possible with placement of electrodes in the occipital region}

\author{
Arshad Ayub, Ira Balakrishnan, \\ Parin Lalwani', Girija Prasad Rath ${ }^{2}$
}

Monitoring the depth of anaesthesia reduces the risk of intra-operative awareness as well as the anaesthetic requirements. ${ }^{[1-3]}$ Thus, it improves the quality of anaesthesia leading to a faster and better recovery. ${ }^{[3,4]}$ Various modalities are available for monitoring the depth of anaesthesia such as bispectral index (BIS), entropy, cerebral state index (CSI) and index of consciousness (IoC). We routinely use IoC monitor in our hospital, which is a symbolic dynamic evaluation of a continuous processed electroencephalography (EEG). The IoC is a scale ranging from 0 to 99 , where adequate anaesthesia is indicated by a value in the range of 40-60. Its manufacturer advocates placement of three silver chloride electrodes, a red and a yellow on the forehead of patient and a green one on the zygomatic bone. Surgeries involving the forehead and face do not allow access for IoC electrodes placement. We tried utility of this monitoring by placing the electrodes on occipital region so as to propose an alternate site for electrode placement. We selected two follow-up patients of frontotempoparietal decompressive craniectomy, posted for cranioplasty under general anaesthesia. The electrodes of an IoC-view monitor (Morpheus Medical, Barcelona, Spain) were placed in occipital region. The red electrode was attached $1-2 \mathrm{~cm}$ just below the inion, yellow electrode one inch lateral to the red and the green electrode just above the mastoid process [Figure 1]. The baseline IoC value of both the patients was 99. Both patients underwent endotracheal anaesthesia after standard induction with intravenous propofol and fentanyl followed by rocuronium to facilitate intubation. Anaesthesia was maintained with isoflurane, $\mathrm{N}_{2} \mathrm{O}$ and $\mathrm{O}_{2}$ in the ratio 1:2. The IoC values, were kept in between 40 and 60 during the maintenance of anaesthesia.

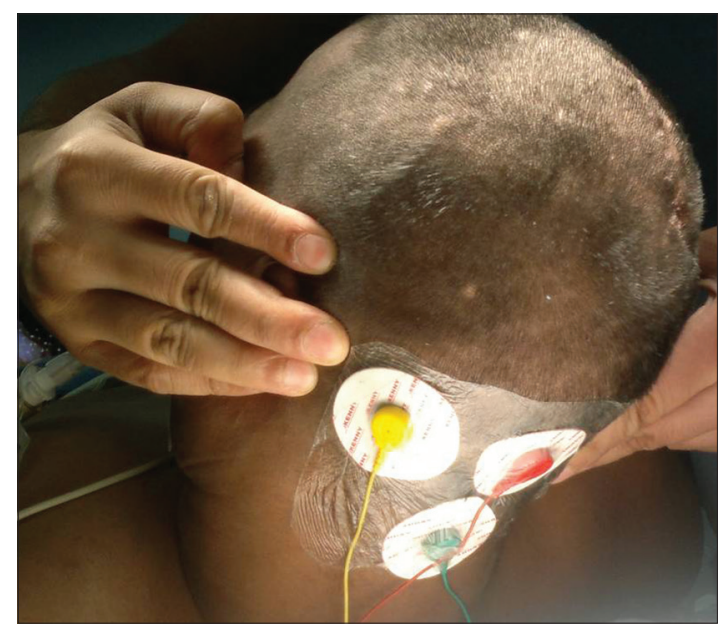

Figure 1: Placement of occipital montages of loC monitor

The IoC is the most recent EEG-based monitor studied and validated to assess depth of anaesthesia. ${ }^{[5]}$ It has been claimed to be better than the traditionally used BIS with a shorter delay time, cost effectiveness, user friendly and higher index stability. Its unique assessment includes spectral ratios, symbolic dynamic evaluation of EEG and EEG suppression ratio (ESR), which provides better suppression of electromyography (EMG). Koch and co-workers showed dominant frontal localisation of EEG. ${ }^{[6]}$ Similarly other studies proved EEG to be a topographic dependent variable and advocated frontal placement of electrodes. ${ }^{[7,8]}$ However, none of those studies compared frontal and occipital montage. Shirhaishi et al. compared these two montages and found strong correlation between them using BIS monitor. ${ }^{[9]}$

To conclude, electrode placement in occipital area was found to be useful for IoC monitoring with an appropriate indication regarding the depth of anaesthesia. However, a well designed, randomised study comparing IoC with other monitors of depth of anaesthesia and electrodes placed in alternate positions, would probably help validating of this alternative site (occipital montage) for placement of IoC electrodes.

\section{REFERENCES}

1. Lennmarken C, Sandin R. Neuromonitoring for awareness during surgery. Lancet 2004;363:1747-8.

2. Kent CD, Domino KB. Awareness: Practice, standards, and the law. Best Pract Res Clin Anaesthesiol 2007;21:369-83.

3. Vakkuri A, Yli-Hankala A, Sandin R, Mustola S, Høymork S, Nyblom $S$, et al. Spectral entropy monitoring is associated

Departments of Anaesthesiology, and ${ }^{2}$ Neuroanaesthesiology, JPN Apex Trauma Centre, All India Institute of Medical Sciences, 'Department of Anaesthesiology, Govind Ballabh Pant Hospital, New Delhi, India

Address for correspondence:

Dr. Girija Prasad Rath, Department of Neuroanaesthesiology, Neurosciences Centre, All-India Institute of Medical Sciences, New Delhi - 110029 , India. E-mail: girijarath@yahoo.co.in 
with reduced propofol use and faster emergence in propofol-nitrous oxide-alfentanil anesthesia. Anesthesiology 2005;103:274-9.

4. Recart A, White PF, Wang A, Gasanova I, Byerly S, Jones SB. Effect of auditory evoked potential index monitoring on anesthetic drug requirements and recovery profile after laparoscopic surgery: A clinical utility study. Anesthesiology 2003;99:813-8

5. Revuelta M, Paniagua P, Campos JM, Fernández JA, Martínez A, Jospin $\mathrm{M}$, et al. Validation of the index of consciousness during sevoflurane and remifentanil anaesthesia: A comparison with the bispectral index and the cerebral state index. $\mathrm{Br} \mathrm{J}$ Anaesth 2008;101:653-8.

6. Kochs E, Bischoff P, Pichlmeier U, Schulte am Esch J. Surgical stimulation induces changes in brain electrical activity during isoflurane/nitrous oxide anesthesia. A topographic electroencephalographic analysis. Anesthesiology 1994;80:1026-34.

7. Hall JD, Lockwood GG. Bispectral index: Comparison of two montages. Br J Anaesth 1998;80:342-4.

8. John ER, Prichep LS. The anesthetic cascade: A theory of how anesthesia suppresses consciousness. Anesthesiology 2005;102:447-71.

9. Shiraishi T, Uchino H, Sagara T, Ishii N. A comparison of frontal and occipital bispectral index values obtained during neurosurgical procedures. Anesth Analg 2004;98:1773-5.

\begin{tabular}{|l|l|}
\hline \multicolumn{2}{|c|}{ Access this article online } \\
\hline Quick Response Code: & Website: \\
\hline & www.jnaccjournal.org \\
\cline { 2 - 2 } & \\
\hline
\end{tabular}

\section{New features on the journal's website}

Optimized content for mobile and hand-held devices

HTML pages have been optimized of mobile and other hand-held devices (such as iPad, Kindle, iPod) for faster browsing speed. Click on [Mobile Full text] from Table of Contents page.

This is simple HTML version for faster download on mobiles (if viewed on desktop, it will be automatically redirected to full HTML version)

\section{E-Pub for hand-held devices}

EPUB is an open e-book standard recommended by The International Digital Publishing Forum which is designed for reflowable content i.e. the text display can be optimized for a particular display device.

Click on [EPub] from Table of Contents page.

There are various e-Pub readers such as for Windows: Digital Editions, OS X: Calibre/Bookworm, iPhone/iPod Touch/iPad: Stanza, and Linux: Calibre/Bookworm.

\section{E-Book for desktop}

One can also see the entire issue as printed here in a 'flip book' version on desktops.

Links are available from Current Issue as well as Archives pages.

Click on View as eBook 